\title{
Safety and Efficacy of the Combination of BCc1 and Hep-S Nanochelating-Based Medicines in Hospitalized COVID-19 Adult Patients: A Randomized, Double-Blind, Placebo-Controlled Clinical Trial
}

\author{
Maryam Hafizi \\ Sodour Ahrar Shargh Company \\ Somayeh Kalanaky \\ Sodour Ahrar Shargh Company \\ Saideh Fakharzadeh \\ Sodour Ahrar Shargh Company \\ Atefeh Fakharian \\ Shahid Beheshti university od medical Sciences \\ Somayeh Lookzadeh \\ Shahid Beheshti University of Medical Sciences \\ Esmaeil Mortaz \\ Shahid Beheshti University of Medical Sciences School of Nursing and Midwifery \\ Maryam Mirenayat \\ Shahid Beheshti University of Medical Sciences School \\ Jalal Heshmatnia \\ Shahid Beheshti University of Medical Sciences School \\ Mehrdad Bakhshayesh Karam \\ Shahid Beheshti University of Medical Sciences School \\ Homa Zamani \\ Shahid Beheshti University of Medical Sciences School \\ Alireza Nadji \\ Shahid Beheshti University of Medical Sciences School of Nursing and Midwifery \\ Mihan Pourabdollah Toutkaboni \\ Shahid Beheshti University of Medical Sciences School \\ Saeed Oraee-Yazdani \\ Shahid Beheshti University of Medical Sciences School \\ Mohammad Esmaeil Akbari \\ Shahid Beheshti University of Medical Sciences \\ Hamidreza Jamaati \\ Shahid Beheshti University of Medical Sciences School \\ Mohammad Nazaran ( $\square$ mazaran@nanochelatingtechnology.com ) \\ Sodour Ahrar Shargh Company https://orcid.org/0000-0002-9413-2295
}

\section{Research}

Keywords: COVID-19, BCc1, Hep-S, Nanochelating technology, IL-6, Cytokine storm

Posted Date: October 19th, 2021

DOI: https://doi.org/10.21203/rs.3.rs-962691/v1

License: (c) (i) This work is licensed under a Creative Commons Attribution 4.0 International License. Read Full License 


\section{Abstract}

Background: The mortality and morbidity of COVID-19 disease as well as the lack of a proper medication has forced researchers and clinicians to employ urgent efficient technologies to overcome this current pandemic. In the severe forms of COVID-19, the patients develop a cytokine storm syndrome (CSS) where pro-inflammatory cytokines such as IL-6 and TNF-a play a key role in the development of this serious process. The efficiency of nanomedicines - as efficient immunomodulators - that are synthesized based on nanochelating technology have been proved in the previous studies. In the present study, the therapeutic effect of the combination of BCc1 and Hep-S nanomedicines on hospitalized COVID-19 patients was evaluated.

Method: Laboratory-confirmed moderate COVID-19 patients at Masih Daneshvari Hospital were enrolled to participate in a randomized, doubleblind, placebo-controlled study in two separate groups: combination of BCc1 and Hep-S ( $\mathrm{N}=62)$ (treatment) or placebo ( $\mathrm{N}=60)$ (placebo). The primary outcome of the study was evaluating the safety of the nanomedicines combination and its effect on the number of deceased patients, while the secondary outcome was decrease in inflammatory cytokines.

Results: The evaluation of blood biochemical indices as well as clinical symptoms showed that adding the combination of BCc1 and Hep-S nanomedicines to the standard protocol of the treatment caused no adverse effects. The results analysis revealed that 28-day consumption of the nanomedicines led to a significant decrease in the mean level of IL- 6 cytokine of the patients in the treatment group $(p<0.05)$. In addition, the patients in the treatment group had lower TNF-a levels compared to those in the control $(p>0.05)$ and they also showed less need for oxygen therapy. Finally, the number of the deceased patients in the treatment group was $30 \%$ lower than that of the control $(p>0.05)$.

Conclusion: The combination of BCc1 and Hep-S, as safe nanomedicines, inhibits IL-6 as a highly important and well-known cytokine in COVID-19 pathophysiology, and presents a promising view for immunomodulation that can manage CSS and reduce mortality rate in COVID19 patients.

Trial registration IRCTID, IRCT20170731035423N2. Registered 12 Jun 2020, http://www.irct.ir/ IRCT20170731035423N2.

\section{Introduction}

COVID-19 first appeared in China in early 2020 and quickly spread all around the world. This eventually made the World Health Organization (WHO) formally declare the disease as "Global Pandemic" in March 2020. The virus that causes COVID-19 disease is called Severe Acute Respiratory Syndrome Virus No. 2 (SARS-CoV-2)[1] that belongs to the coronavirus family [2,3]. As soon as the virus enters the alveolar epithelial cells, it begins to multiply, triggering a chain of inflammatory and immune responses that lead to Cytokine Storm Syndrome (CSS), lung tissue damage and eventually acute respiratory distress syndrome[4]. Numerous studies have shown that Interleukin-6 (IL-6) is the primary mediator of this process as a proinflammatory cytokine[5-7].

The available therapeutic interventions for this disease can be classified as antiviral drugs, anti-inflammatory drugs, monoclonal antibodies and plasma therapy, the efficacy of which is being studied in various clinical studies[8], and according to recent WHO reports, there is no certain proof of the therapeutic effects of these medicines[9]. One of the major challenges of many of these medicines is their side effects [10], which is sometimes exacerbated in combination therapies[11]. Due to the high prevalence of this disease and the serious economic and psychological damage that it causes as well as the many unknown functional mechanisms of this emerging virus, relying on common points of life cycle and virus replication along with applying efficient technologies is required as key tools in achieving a successful cure for this disease.

Microelements are vital elements whose metabolism modifications substantially affect the immune system responses[12]. Iron and its homeostasis play a critical role in the outcome of viral infections. As the virus relies on iron for replication, it tends to take this vital element out of the body's physiological cycle and seize it for its own survival[13]. Changes in the metabolism of this element in COVID-19 patients have also been studied and proved in several researches[14, 15]. Selenium, on the other hand, is a micromineral element whose role in changing the immune response pattern and increasing antiviral defense has been extensively studied[16, 17]. Researches during the recent pandemic show that the supplementation of this element reduces the risk and severity of COVID-19[18].

Over the last decade, studies on the structures synthesized based on nanochelating technology have demonstrated the therapeutic effects of these medicines in cellular and animal models of various diseases[19-21]. Through intelligent modification of trace elements metabolism and related mechanisms, these medicines can induce immunomodulatory behavior and subsequent therapeutic effects[22, 23]. The previous studies have demonstrated the antioxidant, antineoplastic and immunomodulatory effects of BCc1 nanomedicine (which has iron chelating property) without causing any side effects in several cellular and animal models as well as clinical trials[21, 24].

Given the established role of iron and selenium metabolism in the immune system responses and outcomes of viral diseases, the current study aimed to assess the safety as well as the therapeutic impact of adding the combination of BCc1 (having iron-chelating property) and Hep-S (selenium-containing) nanomedicines to the standard treatment of hospitalized COVID-19 patients.

\section{Methods}




\section{Trial design}

Eligible COVID-19 patients who were hospitalized at Masih Daneshvari Hospital in Tehran, Iran were enrolled for this randomized, hospital-based, parallel-group, placebo-controlled trial to evaluate the safety and efficacy of the combination of BCc1 and Hep-S nanomedicines in the treatment of moderate COVID-19 patients.

\section{Participants inclusion and exclusion criteria}

Hospitalized confirmed COVID-19 patients, diagnosed via PCR \& CT scanning of the lungs in accordance with WHO diagnosis criteria, were selected and recruited for the present study. All the patients filled out a consent form to participate in this study. It was also made sure that the patients' health conditions would not improve, nor would they be discharged from hospital within 48 hrs from the start of the study. Those patients who were pregnant or in lactation, suffered hereditary immunodeficiency, had a transplant or a record of type 1 diabetes, or were addicted to alcohol or drugs were excluded from the study.

\section{Study setting}

The current study was performed and supervised by nurses and doctors at Masih Daneshvari Hospital. The comprehensive procedure of the trial was explained to the patients by the recruited nurses at the hospital and then an informed written consent form was signed by all the patients.

\section{Interventions}

BCc1 and Hep-S nanomedicines were designed by Sodour Ahrar Shargh Company based on the nanochelating technology [25]. BCc1 characterization and its standard median lethal dose (LD50) is reported in the previous studies[21, 26]. Hep-S is a selenium-containing nanochelating-based structure. The HRTEM image of Hep-S was captured using Philips CM30-250KV model transmission electron microscope at University of Tehran Science and Technology Park. The HRTEM image of Hep-S indicates that the size of this nanomedicine is approximately 22.7nm.

Hep-S toxicity was evaluated based on the guidelines of the Organization for Economic Co-operation and Development (OECD, guideline 420) regulations and in accordance with the LD50 evaluation test; these tests were conducted in the School of Pharmacy at Tehran University of Medical Sciences. The toxicity report of Hep-S shows that i.p LD50 of this structure is $54 \mathrm{mg} / \mathrm{kg}$ (Figure 1). Active pharmaceutical ingredient (API) synthesis of BCc1 and Hep-S nanomedicines was carried out by using the nanochelating technology in the laboratory of Sodour Ahrar Shargh Company.

The two nanomedicines of BCc1 and Hep-S were used at the same time in the form of syrup as a two-medicine package to evaluate its effect in comparison with placebo. Two types of placebo syrup were administered to the patients in the placebo group. Both the COVID-19 and placebo syrup were exactly identical in terms of shape and size.

Each nanomedicine was provided in a separate bottle along with instructions for each. The patients in the treatment group received BCc1 twice a

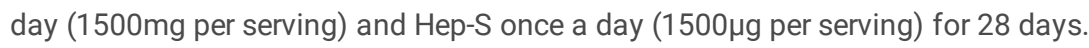

\section{Outcomes}

Safety parameters (clinical and laboratory features of the patients) and morality rate were defined as the primary outcome of the present study, while the levels of cytokine storm indices were defined as the secondary outcome.

\section{Randomization, blinding and allocation}

The patients, clinicians and nurses were all blinded to the treatment allocation. The patients were assigned to the study after the clinicians screened them based on the inclusion and exclusion criteria. They were then randomly assigned to the treatment or placebo group based on a block randomization form prepared and given to the nurses by the researcher in charge. All the patients signed an informed written consent form.

\section{Sample size}

Given the fact that this experiment was the first clinical trial conducted on the impact of BCc1 and Hep-S nanomedicines package on COVID-19 patients, the preliminary results of a pilot study on the collaborators of this project were used to allocate 62 patients to the treatment group and 60 patients to the placebo in the present study.

\section{Withdrawal}

At any point during the study, the patients were all allowed to withdraw from the experiment and were not asked to provide the reason, but in case of withdrawal, they allowed the continuation of data collection.

\section{Follow-up}


During the hospitalization period, the medicines were administered to the patients by the nurses according to the clinicians' prescription. The patients were followed up $24 \mathrm{hrs}$ after being discharged from the hospital. They were also contacted on days 10, 15, 20 and 27 by the study team to record their clinical status and make sure if the patients had taken the medicines according to Table 1 . In case of any sickness caused by the medicines, the reasons were checked.

Table-1. Titles of Clinical Score.

\begin{tabular}{|c|c|c|c|}
\hline Title & $\begin{array}{l}\text { NOT } \\
\text { (2) }\end{array}$ & $\begin{array}{l}\text { Sometimes } \\
\text { (1) }\end{array}$ & $\begin{array}{l}\text { Yes } \\
(0)\end{array}$ \\
\hline Nausea & & & \\
\hline Fever & & & \\
\hline Diarrhea & & & \\
\hline Headache & & & \\
\hline Vertigo & & & \\
\hline Anorexia & & & \\
\hline Anosmia & & & \\
\hline Sore throat & & & \\
\hline Cough & & & \\
\hline Body pain & & & \\
\hline Lethargy & & & \\
\hline Body Chill & & & \\
\hline Shortness of breath at rest & & & \\
\hline Shortness of breath in activity & & & \\
\hline Satisfaction of patients & & & \\
\hline oxygen therapy & & & \\
\hline
\end{tabular}

Besides, the patients had access to the researcher in charge by phone calls to consult with her for any reason at any time. Trial completion was defined as consuming the nanomedicines for 28 days or discontinuation of the follow-ups for any cause.

\section{Data collection}

During the study, the researcher in charge collected the information and checked for any missing values and inconsistencies. Full details of data collection procedure are available upon request.

\section{Assessments}

- Blood samples were taken from all 122 patients in the treatment and placebo groups on day zero (before medicines consumption), at discharge and 28 days after consumption (end of the treatment) to measure biochemical indices (Table 2). All tests were carried out in the clinical laboratory of Masih Daneshvari Hospital according to the standard protocols of the hospital.

- CT images of all the patients were taken according to standard protocols at admission and on day 28 (end of the treatment). Following that, the images were scored based on the standard protocol to analyze the data[27].

- Eleven patients from each group (22 samples in total) were randomly selected to measure serum levels of INF-y, TNF-a and IL-6 cytokines before the start of the study, at discharge and after the end of the treatment. ELISA kits were used to measure TNFa (R\&D Systems, UK), IFNY (Thermo Fisher, Waltham, Massachusetts, USA) and IL-6 (R\&D Systems, UK) according to the manufactures' instruction[28].

- The clinical status of all the patients was recorded according to an assessment questionnaire before the start of the treatment and on days 3 , $6,10,15,20$ and 27 (Table 1). The responses were then scored with the highest number representing better health conditions. 
Table 2

Titles of laboratory features.

\begin{tabular}{|c|c|c|c|c|}
\hline & laboratory features & Before medicine consumption & At discharge of hospital & 28 days after consumption \\
\hline 1 & $\mathrm{CBC}$ & * & * & * \\
\hline 2 & AST & * & * & * \\
\hline 3 & ALT & * & * & * \\
\hline 4 & CD 4 & * & * & * \\
\hline 5 & CD 8 & * & * & * \\
\hline 6 & CD 20 & * & * & * \\
\hline 7 & NK & * & * & * \\
\hline 8 & $\lg G$ & * & * & * \\
\hline 9 & $\lg M$ & * & * & * \\
\hline 10 & Ferritin & * & $\longrightarrow$ & * \\
\hline 11 & Bill. Total & * & * & * \\
\hline 12 & IRON.SEROM & * & $\longrightarrow$ & * \\
\hline 13 & TIBC & * & 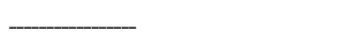 & * \\
\hline 14 & ESR & * & * & * \\
\hline 15 & CRP & * & * & * \\
\hline
\end{tabular}

\section{Statistical analysis}

Descriptive statistics were expressed using mean \pm standard deviation (SD), median (Q1, Q3) and minimum-maximum. The mean difference of variables between the nanomedicines and placebo was evaluated using independent t-test or Mann-Whitney- $U$ test. The repeated measure analysis was used to assess the impact of time and treatment on the markers. The post-hoc analysis was performed between times using Bonferroni multiple comparison. The estimated marginal means of markers are shown using profile plot by time and treatment. The Wilcoxon Signed Ranks Test was used to compare the markers at different times relative to the value of the marker in the baseline. All analyzes were performed by $\mathrm{R}$ (version 4.0.2) and SPSS (version 26). P-values of less than 0.05 were regarded as statistically significant.

\section{Results}

\section{Patients' disposition and characteristics}

The patients were recruited between Oct 2, 2020 and March 20, 2021. Initially, 132 patients were randomly recruited. Due to ineligibility, incomplete histological confirmation, among other reasons, ten of those were excluded from the study (Table 3, prepared according to Consolidated Standards of Reporting Trials Form)[29]. The patients' demographic information is shown in Tables 4. All the patients received similar antiviral therapy, including remdesivir, dexamethasone and prednisolone.

Tables-3. Consort flow diagram of study. 


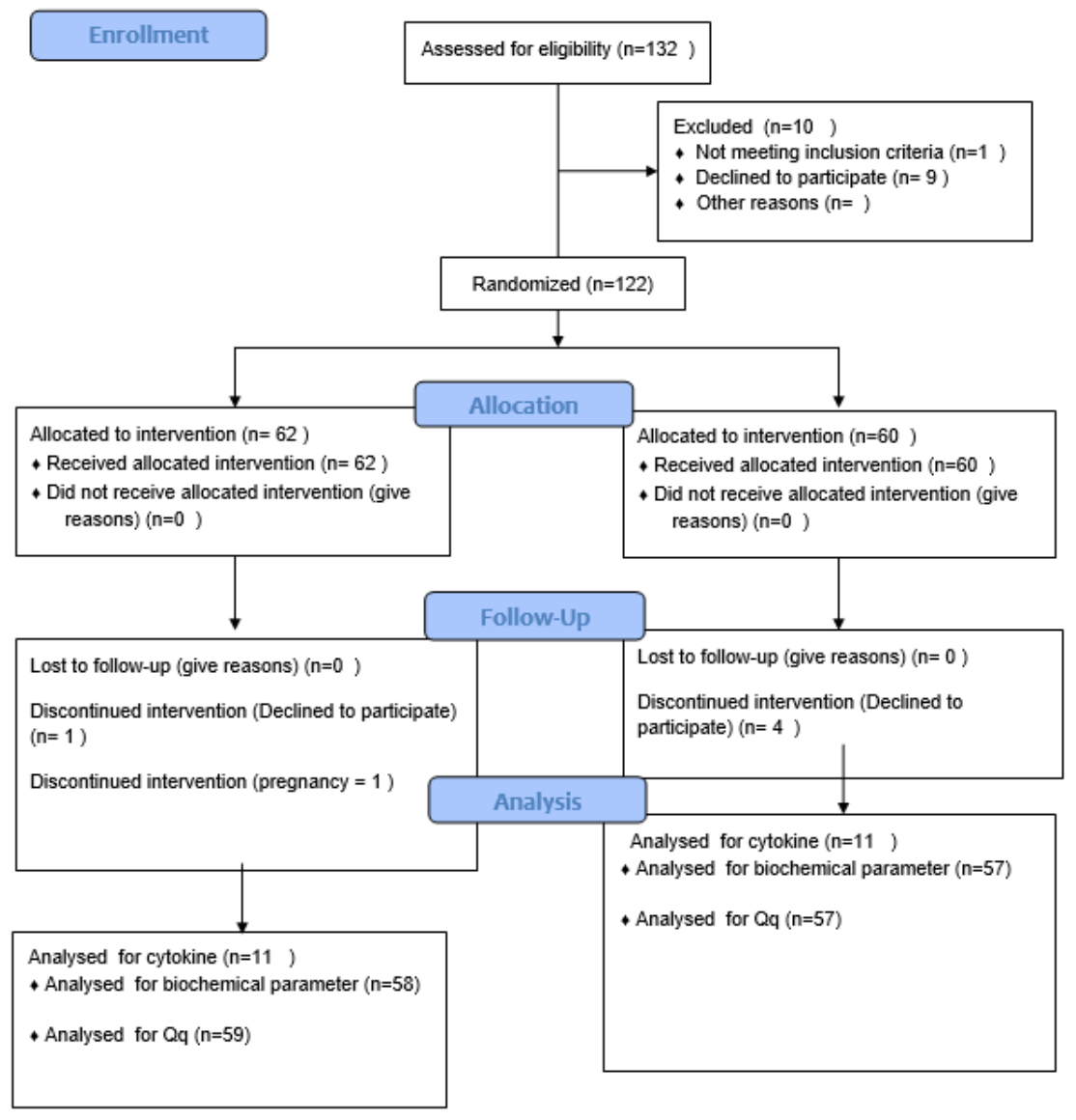

Table 4

Descriptive Statistics of patients in the Combination of BCc1 and Hep-S group with patients in the placebo group.

\begin{tabular}{|llll|}
\hline Variable & Level & Drug (N=62) & Placebo (N=60) \\
\hline Sex & Male & $29(44.6 \%)$ & $37(64.9 \%)$ \\
\cline { 2 - 4 } & Female & $36(55.4 \%)$ & $20(35.1 \%)$ \\
\hline Age & Mean \pm SD & $50.65 \pm 11.82$ & $52.23 \pm 13.46$ \\
\cline { 2 - 4 } & Median (IQR) & $53.00(39.50,59.50)$ & $42.00(53.00,61.00)$ \\
\hline Difference time of discharge and hospitalization & Mean \pm SD & $6.92 \pm 4.09$ & $6.25 \pm 1.71$ \\
\cline { 2 - 4 } & Median (IQR) & $6.00(5.00,7.00)$ & $6.00(5.00,7.00)$ \\
\hline Difference time of discharge and taking intervntion & Mean \pm SD & $5.78 \pm 4.16$ & $5.19 \pm 1.59$ \\
\cline { 2 - 4 } & Median (IQR) & $5.00(4.00,6.00)$ & $5.00(4.00,6.00)$ \\
\hline a: The exact Pearson chi-square, b: The independent t-test, c: The exact Mann-Whitney test & \\
\hline
\end{tabular}

\section{Outcome and estimation}

\subsection{Serum cytokine levels}

Measuring biomarkers before the start of the study, at discharge and the end of the treatment showed changes at their levels in the treatment group, especially the levels of COVID-19 cytokines; IL-6, TNF-a and IFN-Y (Figure 2 \& Table 5). 
Table 5

Descriptive Statistics of Cytokines Tests by Group (Drug vs. Placebo).

\begin{tabular}{|c|c|c|c|c|c|c|c|}
\hline \multirow{2}{*}{$\begin{array}{l}\text { Within Subjects } \\
\text { Effect }\end{array}$} & \multirow{2}{*}{$\begin{array}{l}\text { Mauchly's } \\
\text { W }\end{array}$} & \multirow{2}{*}{$\begin{array}{l}\text { Approx. Chi- } \\
\text { Square }\end{array}$} & \multirow[t]{2}{*}{ df } & \multirow[t]{2}{*}{ Sig. } & \multicolumn{3}{|l|}{ Epsilon ${ }^{b}$} \\
\hline & & & & & $\begin{array}{l}\text { Greenhouse- } \\
\text { Geisser }\end{array}$ & $\begin{array}{l}\text { Huynh- } \\
\text { Feldt }\end{array}$ & $\begin{array}{l}\text { Lower- } \\
\text { bound }\end{array}$ \\
\hline
\end{tabular}

\begin{tabular}{|lllllllll|}
\hline IL-6 & Time & .903 & 1.844 & 2 & .398 & .911 & 1.000 & .500 \\
\hline TNF & Time & .710 & 6.508 & 2 & .039 & .775 & .870 & .500 \\
INFGama & Time & .438 & 15.699 & 2 & .000 & .640 & .699 & .500 \\
\hline
\end{tabular}

The results showed that there was a downward trend of $77 \%$ in IL-6 during the nanomedicines consumption treatment, revealing its significant effect on IL-6 cytokine $(p<0.05)$. By contrast, there was no significant difference at IL- 6 level in the placebo group, and yet it increased by $18 \%$. Similarly, there was $21 \%$ decrease in TNF-a cytokine level in the treatment group, while there was $31 \%$ increase in the level of this cytokine in the placebo ( $p$ > 0.05). Finally, IFN-y level in the treatment group increased by $11 \%$, whereas it decreased by $34 \%$ in the placebo. In addition, In addition, the levels of ESR and CRP had no significant difference between groups ( $p>0.05)$ (Figure 3 and Table 6)

\subsection{Immunophenotyping of blood cells}

Four CD markers of CD4, CD8, CD20 and NK were analyzed in this study, and the results showed that there was no significant difference between the studied groups in terms of CD4, CD8 and CD20 count ratio $(P>0.05)$. However, there was downward trend in NK cells count in the treatment group after discharge until the end of the treatment compared with the placebo (Figure 4$)(p>0.05)$.

\subsection{Serum antibody data}

As depicted in Figure 5, the serum levels analysis of antibodies against SARS-COV-2 showed that the serum levels of IgM decreased from discharge until the end of the treatment in the treatment group, while it increased in the placebo $(p>0.05)$. However, there were no significant changes at serum IgG levels between the treatment and placebo groups (Figure 5).

\subsection{Safety parameters}

- Biological and laboratory parameters

In order to determine the safety of the combination of the nanomedicines, blood samples were taken and analyzed on day zero, at discharge and the end of the treatment. The results indicated that all the measured biological and laboratory parameters according to Table 1 were at normal range on day 28 , and there was no significant difference between the treatment and placebo groups (Table 7).

- Clinical parameters

The body temperature comparison of the hospitalized COVID-19 patients in the treatment and placebo groups on the studied days of the treatment are presented in the box plot graph. As can be seen, there was no significant difference between the groups in terms of the patients' body temperature. Clinical scores of all participants were evaluated according to Table 1, the results of which demonstrated that there was no significant difference between both groups, so it can be claimed that the nanomedicines had no negative impact on the clinical indices of the patients (Figure 6) As the oxygen therapy independency diagram demonstrates, the treatment group showed less dependency to oxygen therapy than the placebo group. In addition, the patients in the treatment group had more satisfaction than the patients in the placebo group.

\subsection{Evaluation of SPO2 and lungs images after treatment}

The SPO2 (oxygen saturation percentage) analysis indicates that there was no significant difference between the studied groups in terms of average SPO2.

The comparison of the CT images of both groups before and after the treatment shows that the pulmonary involvement in the treatment group was $6 \%$ less than that of the placebo at the end of the treatment $(P>0.05)$, (Figure 7 ).

\subsection{Survival}

The results of the statistical analyses showed two and three death cases in the treatment and placebo groups, respectively. The comparisons also indicated that the deceased patients in the treatment group lived four days longer than the deceased in the placebo group (P > 0.05), (Table 8).

Page $7 / 23$ 
Tables-7. A) Descriptive Statistics of Blood Tests by Group (Drug vs. Placebo). 


\begin{tabular}{|c|c|c|c|c|c|c|}
\hline Variables & Time point & Group & Mean \pm SD & Median (Q1, Q3) & Min, Max & P-value \\
\hline \multirow[t]{6}{*}{ HB } & Before taking the drug & Drug & $13.33 \pm 1.85$ & $13.40(12.50,14.60)$ & $8.00,17.00$ & 0.137 \\
\hline & & Placebo & $13.79 \pm 1.64$ & $13.90(12.50,15.08)$ & $10.10,17.80$ & \\
\hline & Time of discharge & Drug & $14.23 \pm 1.91$ & $14.60(13.08,15.38)$ & $9.20,18.20$ & 0.484 \\
\hline & & Placebo & $14.46 \pm 1.61$ & $14.70(13.40,15.40)$ & $10.40,17.50$ & \\
\hline & 28 days after taking the drug & Drug & $13.92 \pm 1.72$ & $13.90(12.85,14.95)$ & $7.70,17.40$ & 0.729 \\
\hline & & Placebo & $13.79 \pm 1.88$ & $14.00(13.10,15.00)$ & $5.85,17.10$ & \\
\hline \multirow[t]{6}{*}{ RBC } & Before taking the drug & Drug & $4.71 \pm 0.48$ & $4.70(4.40,5.12)$ & $3.04,5.52$ & 0.006 \\
\hline & & Placebo & $4.98 \pm 0.58$ & $4.99(4.56,5.25)$ & $3.45,7.04$ & \\
\hline & Time of discharge & Drug & $5.04 \pm 0.65$ & $4.91(4.74,5.29)$ & $3.79,8.58$ & 0.170 \\
\hline & & Placebo & $5.22 \pm 0.75$ & $5.23(4.74,5.62)$ & $3.01,7.36$ & \\
\hline & 28 days after taking the drug & Drug & $4.85 \pm 0.48$ & $4.87(4.60,5.23)$ & $3.12,5.75$ & 0.188 \\
\hline & & Placebo & $4.99 \pm 0.58$ & $4.94(4.63,5.29)$ & $4.05,7.17$ & \\
\hline \multirow[t]{6}{*}{ HCT } & Before taking the drug & Drug & $39.05 \pm 4.26$ & $39.70(36.60,42.30)$ & $26.40,47.00$ & 0.095 \\
\hline & & Placebo & $40.24 \pm 3.64$ & $41.05(37.55,42.95)$ & $29.90,47.60$ & \\
\hline & Time of discharge & Drug & $41.31 \pm 4.21$ & $41.85(39.53,43.15)$ & $31.40,50.00$ & 0.155 \\
\hline & & Placebo & $42.46 \pm 4.58$ & $43.10(40.30,44.75)$ & $29.60,56.40$ & \\
\hline & 28 days after taking the drug & Drug & $41.23 \pm 4.61$ & $42.00(38.60,44.55)$ & $24.40,48.60$ & 0.537 \\
\hline & & Placebo & $41.76 \pm 3.62$ & $41.90(39.60,44.50)$ & $32.70,50.30$ & \\
\hline \multirow[t]{6}{*}{ MCV } & Before taking the drug & Drug & $83.07 \pm 6.39$ & $84.50(81.40,87.10)$ & $57.80,92.10$ & 0.178 \\
\hline & & Placebo & $81.36 \pm 7.80$ & $83.00(80.00,85.80)$ & $56.80,94.20$ & \\
\hline & Time of discharge & Drug & $83.03 \pm 6.45$ & $84.20(81.20,86.50)$ & $60.00,94.10$ & 0.272 \\
\hline & & Placebo & $81.56 \pm 8.05$ & $82.85(79.33,85.78)$ & $56.90,98.30$ & \\
\hline & 28 days after taking the drug & Drug & $83.91 \pm 9.15$ & $85.55(81.48,89.68)$ & $50.80,95.00$ & 0.837 \\
\hline & & Placebo & $84.27 \pm 7.83$ & $85.70(82.10,88.70)$ & $60.40,96.50$ & \\
\hline \multirow[t]{6}{*}{ WBC } & Before taking the drug & Drug & $7.55 \pm 3.63$ & $6.80(4.90,8.50)$ & $2.24,22.20$ & 0.308 \\
\hline & & Placebo & $8.23 \pm 3.89$ & $7.15(5.50,10.23)$ & $2.70,18.90$ & \\
\hline & Time of discharge & Drug & $10.47 \pm 4.41$ & $9.65(7.70,12.25)$ & $4.10,26.60$ & 0.673 \\
\hline & & Placebo & $10.78 \pm 3.46$ & $10.80(8.20,12.48)$ & $4.54,20.30$ & \\
\hline & 28 days after taking the drug & Drug & $8.02 \pm 2.61$ & $7.79(5.77,9.28)$ & $3.38,14.00$ & 0.638 \\
\hline & & Placebo & $7.78 \pm 2.41$ & $7.28(6.02,9.40)$ & $3.04,15.32$ & \\
\hline \multirow[t]{6}{*}{ Lymph } & Before taking the drug & Drug & $18.99 \pm 8.77$ & $17.00(13.20,24.00)$ & $5.00,45.00$ & 0.050 \\
\hline & & Placebo & $15.99 \pm 8.25$ & $14.00(9.78,21.50)$ & $2.00,39.00$ & \\
\hline & Time of discharge & Drug & $16.51 \pm 10.21$ & $14.00(11.08,18.30)$ & $5.50,57.00$ & 0.090 \\
\hline & & Placebo & $13.30 \pm 10.34$ & $12.00(8.13,15.95)$ & $1.00,81.00$ & \\
\hline & 28 days after taking the drug & Drug & $30.64 \pm 10.96$ & $29.85(25.88,39.48)$ & $0.21,47.80$ & 0.903 \\
\hline & & Placebo & $30.39 \pm 9.47$ & $28.65(25.10,35.90)$ & $0.28,52.00$ & \\
\hline \multirow[t]{5}{*}{ Neut } & Before taking the drug & Drug & $74.69 \pm 11.16$ & $77.00(67.60,83.00)$ & $46.00,93.00$ & 0.027 \\
\hline & & Placebo & $78.95 \pm 10.11$ & $81.00(70.25,87.00)$ & $49.97,94.00$ & \\
\hline & Time of discharge & Drug & $78.02 \pm 10.49$ & $81.40(74.85,84.78)$ & $36.00,89.70$ & 0.262 \\
\hline & & Placebo & $80.26 \pm 11.25$ & $81.50(76.23,85.30)$ & $16.00,95.00$ & \\
\hline & & & Page $9 / 23$ & & & \\
\hline
\end{tabular}




\begin{tabular}{|c|c|c|c|c|c|c|}
\hline & 28 days after taking the drug & Drug & $57.06 \pm 11.49$ & $56.80(49.33,63.33)$ & $34.00,92.00$ & 0.844 \\
\hline & & Placebo & $56.63 \pm 9.59$ & $57.70(49.50,63.00)$ & $36.00,74.40$ & \\
\hline \multirow[t]{6}{*}{ Ferritin } & Before taking the drug & Drug & $467.83 \pm 482.72$ & $338.00(162.50,564.50)$ & $4.00,2000.00$ & 0.690 \\
\hline & & Placebo & $505.00 \pm 355.59$ & $407.00(236.00,739.00)$ & $36.00,1660.00$ & \\
\hline & Time of discharge & Drug & $425.70 \pm 356.34$ & $421.00(51.25,672.00)$ & $27.00,1105.00$ & 0.837 \\
\hline & & Placebo & $391.20 \pm 382.63$ & $248.00(120.00,580.25)$ & $47.00,1189.00$ & \\
\hline & 28 days after taking the drug & Drug & $241.37 \pm 203.53$ & $196.50(83.00,349.75)$ & $6.00,762.00$ & 0.961 \\
\hline & & Placebo & $243.85 \pm 200.92$ & $224.00(67.00,348.00)$ & $20.00,737.00$ & \\
\hline \multirow[t]{6}{*}{ AST } & Before taking the drug & Drug & $44.28 \pm 18.27$ & $40.00(30.00,56.00)$ & $14.00,117.00$ & 0.366 \\
\hline & & Placebo & $47.63 \pm 23.28$ & $41.00(31.25,55.00)$ & $15.00,127.00$ & \\
\hline & Time of discharge & Drug & $56.89 \pm 49.51$ & $43.50(32.25,60.50)$ & $15.00,341.00$ & 0.303 \\
\hline & & Placebo & $49.53 \pm 22.12$ & $47.00(28.50,60.50)$ & $18.00,106.00$ & \\
\hline & 28 days after taking the drug & Drug & $28.38 \pm 14.89$ & $25.00(21.00,31.25)$ & $13.00,112.00$ & 0.808 \\
\hline & & Placebo & $29.07 \pm 12.41$ & $25.00(20.75,34.50)$ & $15.00,69.00$ & \\
\hline \multirow[t]{6}{*}{ ALT } & Before taking the drug & Drug & $42.04 \pm 24.37$ & $35.00(28.00,48.00)$ & $9.00,131.00$ & 0.025 \\
\hline & & Placebo & $53.72 \pm 32.58$ & $41.50(30.25,71.00)$ & $11.00,191.00$ & \\
\hline & Time of discharge & Drug & $86.70 \pm 63.93$ & $63.00(41.00,117.25)$ & $22.00,416.00$ & 0.203 \\
\hline & & Placebo & $100.72 \pm 55.65$ & $90.00(59.00,129.00)$ & $20.00,252.00$ & \\
\hline & 28 days after taking the drug & Drug & $38.96 \pm 28.54$ & $31.00(24.00,42.50)$ & $4.00,156.00$ & 0.466 \\
\hline & & Placebo & $43.35 \pm 29.92$ & $36.50(26.50,50.50)$ & $12.00,160.00$ & \\
\hline \multirow[t]{6}{*}{ Bill.Total } & Before taking the drug & Drug & $0.62 \pm 0.78$ & $0.50(0.30,0.70)$ & $0.10,6.50$ & 0.717 \\
\hline & & Placebo & $0.58 \pm 0.24$ & $0.60(0.40,0.70)$ & $0.20,1.30$ & \\
\hline & Time of discharge & Drug & $0.57 \pm 0.32$ & $0.50(0.40,0.80)$ & $0.10,2.00$ & 0.401 \\
\hline & & Placebo & $0.62 \pm 0.33$ & $0.60(0.40,0.80)$ & $0.04,2.00$ & \\
\hline & 28 days after taking the drug & Drug & $0.92 \pm 0.48$ & $0.80(0.60,1.13)$ & $0.20,2.70$ & 0.927 \\
\hline & & Placebo & $0.93 \pm 0.53$ & $0.70(0.60,1.20)$ & $0.40,2.70$ & \\
\hline \multirow[t]{6}{*}{ IRON.SEROM } & Before taking the drug & Drug & $56.16 \pm 24.18$ & $51.75(42.25,69.75)$ & $18.00,124.00$ & 0.391 \\
\hline & & Placebo & $61.28 \pm 25.66$ & $51.20(43.00,81.00)$ & $25.00,125.90$ & \\
\hline & Time of discharge & Drug & $88.89 \pm 36.83$ & $80.00(62.00,124.00)$ & $29.70,159.00$ & 0.115 \\
\hline & & Placebo & $102.71 \pm 41.60$ & $98.60(75.40,129.00)$ & $30.00,258.00$ & \\
\hline & 28 days after taking the drug & Drug & $82.94 \pm 32.33$ & $81.00(59.45,108.53)$ & $20.00,152.00$ & 0.820 \\
\hline & & Placebo & $81.44 \pm 26.37$ & $76.00(68.00,94.00)$ & $24.00,155.00$ & \\
\hline
\end{tabular}


Tables-7. B) Tests of Within-Subjects Effects.

\begin{tabular}{|c|c|c|c|c|c|c|c|c|c|c|}
\hline Variable & Source & & $\begin{array}{l}\text { Type III } \\
\text { Sum of } \\
\text { Squares }\end{array}$ & df & $\begin{array}{l}\text { Mean } \\
\text { Square }\end{array}$ & $\mathbf{F}$ & Sig. & $\begin{array}{l}\text { Partial } \\
\text { Eta } \\
\text { Squared }\end{array}$ & $\begin{array}{l}\text { Noncent. } \\
\text { Parameter }\end{array}$ & $\begin{array}{l}\text { Observed } \\
\text { Power }^{\mathrm{a}}\end{array}$ \\
\hline HB & Time & $\begin{array}{l}\text { Greenhouse- } \\
\text { Geisser }\end{array}$ & 24.665 & 1.777 & 13.882 & 12.693 & .000 & .121 & 22.552 & .993 \\
\hline HB & $\begin{array}{l}\text { Time * } \\
\text { Group1 }\end{array}$ & $\begin{array}{l}\text { Greenhouse- } \\
\text { Geisser }\end{array}$ & 3.164 & 1.777 & 1.781 & 1.628 & .202 & .017 & 2.893 & .321 \\
\hline $\mathrm{HB}$ & Error(Time) & $\begin{array}{l}\text { Greenhouse- } \\
\text { Geisser }\end{array}$ & 178.778 & 163.459 & 1.094 & & & & & \\
\hline RBC & Time & $\begin{array}{l}\text { Greenhouse- } \\
\text { Geisser }\end{array}$ & 3.995 & 1.874 & 2.132 & 16.616 & .000 & .150 & 31.139 & .999 \\
\hline RBC & $\begin{array}{l}\text { Time * } \\
\text { Group1 }\end{array}$ & $\begin{array}{l}\text { Greenhouse- } \\
\text { Geisser }\end{array}$ & .230 & 1.874 & .123 & .955 & .382 & .010 & 1.790 & .208 \\
\hline RBC & Error(Time) & $\begin{array}{l}\text { Greenhouse- } \\
\text { Geisser }\end{array}$ & 22.599 & 176.159 & .128 & & & & & \\
\hline HCT & Time & $\begin{array}{l}\text { Sphericity } \\
\text { Assumed }\end{array}$ & 218.386 & 2 & 109.193 & 18.948 & .000 & .169 & 37.895 & 1.000 \\
\hline HCT & $\begin{array}{l}\text { Time * } \\
\text { Group1 }\end{array}$ & $\begin{array}{l}\text { Sphericity } \\
\text { Assumed }\end{array}$ & 6.436 & 2 & 3.218 & .558 & .573 & .006 & 1.117 & .142 \\
\hline HCT & Error(Time) & $\begin{array}{l}\text { Sphericity } \\
\text { Assumed }\end{array}$ & 1071.904 & 186 & 5.763 & & & & & \\
\hline MCV & Time & $\begin{array}{l}\text { Greenhouse- } \\
\text { Geisser }\end{array}$ & 250.180 & 1.376 & 181.793 & 13.127 & .000 & .125 & 18.065 & .982 \\
\hline MCV & $\begin{array}{l}\text { Time * } \\
\text { Group1 }\end{array}$ & $\begin{array}{l}\text { Greenhouse- } \\
\text { Geisser }\end{array}$ & 52.034 & 1.376 & 37.810 & 2.730 & .088 & .029 & 3.757 & .439 \\
\hline MCV & Error(Time) & $\begin{array}{l}\text { Greenhouse- } \\
\text { Geisser }\end{array}$ & 1753.428 & 126.609 & 13.849 & & & & & \\
\hline WBC & Time & $\begin{array}{l}\text { Sphericity } \\
\text { Assumed }\end{array}$ & 471.659 & 2 & 235.829 & 32.899 & .000 & .259 & 65.797 & 1.000 \\
\hline WBC & $\begin{array}{l}\text { Time * } \\
\text { Group1 }\end{array}$ & $\begin{array}{l}\text { Sphericity } \\
\text { Assumed }\end{array}$ & 12.490 & 2 & 6.245 & .871 & .420 & .009 & 1.742 & .198 \\
\hline WBC & Error(Time) & $\begin{array}{l}\text { Sphericity } \\
\text { Assumed }\end{array}$ & 1347.652 & 188 & 7.168 & & & & & \\
\hline Lymph & Time & $\begin{array}{l}\text { Greenhouse- } \\
\text { Geisser }\end{array}$ & 13103.940 & 1.717 & 7632.120 & 82.082 & .000 & .472 & 140.931 & 1.000 \\
\hline Lymph & $\begin{array}{l}\text { Time * } \\
\text { Group1 }\end{array}$ & $\begin{array}{l}\text { Greenhouse- } \\
\text { Geisser }\end{array}$ & 15.020 & 1.717 & 8.748 & .094 & .883 & .001 & .162 & .063 \\
\hline Lymph & Error(Time) & $\begin{array}{l}\text { Greenhouse- } \\
\text { Geisser }\end{array}$ & 14687.261 & 157.959 & 92.981 & & & & & \\
\hline Neut & Time & $\begin{array}{l}\text { Sphericity } \\
\text { Assumed }\end{array}$ & 29079.408 & 2 & 14539.704 & 160.137 & .000 & .633 & 320.273 & 1.000 \\
\hline Neut & $\begin{array}{l}\text { Time * } \\
\text { Group1 }\end{array}$ & $\begin{array}{l}\text { Sphericity } \\
\text { Assumed }\end{array}$ & 78.323 & 2 & 39.162 & .431 & .650 & .005 & .863 & .119 \\
\hline Neut & Error(Time) & $\begin{array}{l}\text { Sphericity } \\
\text { Assumed }\end{array}$ & 16887.995 & 186 & 90.796 & & & & & \\
\hline Ferritin & Time & $\begin{array}{l}\text { Sphericity } \\
\text { Assumed }\end{array}$ & 183646.752 & 2 & 91823.376 & 1.732 & .226 & .257 & 3.465 & .281 \\
\hline Ferritin & $\begin{array}{l}\text { Time * } \\
\text { Group1 }\end{array}$ & $\begin{array}{l}\text { Sphericity } \\
\text { Assumed }\end{array}$ & 1397.610 & 2 & 698.805 & .013 & .987 & .003 & .026 & .051 \\
\hline Ferritin & Error(Time) & $\begin{array}{l}\text { Sphericity } \\
\text { Assumed }\end{array}$ & 530063.533 & 10 & 53006.353 & & & & & \\
\hline AST & Time & $\begin{array}{l}\text { Greenhouse- } \\
\text { Geisser }\end{array}$ & 27066.771 & 1.788 & 15138.097 & 31.472 & .000 & .255 & 56.271 & 1.000 \\
\hline
\end{tabular}




\begin{tabular}{|c|c|c|c|c|c|c|c|c|c|c|}
\hline Variable & Source & & $\begin{array}{l}\text { Type III } \\
\text { Sum of } \\
\text { Squares }\end{array}$ & $d f$ & $\begin{array}{l}\text { Mean } \\
\text { Square }\end{array}$ & $F$ & Sig. & $\begin{array}{l}\text { Partial } \\
\text { Eta } \\
\text { Squared }\end{array}$ & $\begin{array}{l}\text { Noncent. } \\
\text { Parameter }\end{array}$ & $\begin{array}{l}\text { Observed } \\
\text { Power }\end{array}$ \\
\hline AST & $\begin{array}{l}\text { Time* } \\
\text { Group1 }\end{array}$ & $\begin{array}{l}\text { Greenhouse- } \\
\text { Geisser }\end{array}$ & 511.636 & 1.788 & 286.152 & .595 & .535 & .006 & 1.064 & .142 \\
\hline AST & Error(Time) & $\begin{array}{l}\text { Greenhouse- } \\
\text { Geisser }\end{array}$ & 79122.678 & 164.495 & 481.003 & & & & & \\
\hline ALT & Time & $\begin{array}{l}\text { Greenhouse- } \\
\text { Geisser }\end{array}$ & 150147.050 & 1.553 & 96703.075 & 48.829 & .000 & .347 & 75.815 & 1.000 \\
\hline ALT & $\begin{array}{l}\text { Time* } \\
\text { Group1 }\end{array}$ & $\begin{array}{l}\text { Greenhouse- } \\
\text { Geisser }\end{array}$ & 910.287 & 1.553 & 586.276 & .296 & .688 & .003 & .460 & .091 \\
\hline ALT & Error(Time) & $\begin{array}{l}\text { Greenhouse- } \\
\text { Geisser }\end{array}$ & 282895.072 & 142.845 & 1980.437 & & & & & \\
\hline Bill.Total & Time & $\begin{array}{l}\text { Greenhouse- } \\
\text { Geisser }\end{array}$ & 6.072 & 1.721 & 3.528 & 11.316 & .000 & .133 & 19.478 & .984 \\
\hline Bill.Total & $\begin{array}{l}\text { Time * } \\
\text { Group1 }\end{array}$ & $\begin{array}{l}\text { Greenhouse- } \\
\text { Geisser }\end{array}$ & .152 & 1.721 & .088 & .283 & .720 & .004 & .488 & .091 \\
\hline Bill.Total & Error(Time) & $\begin{array}{l}\text { Greenhouse- } \\
\text { Geisser }\end{array}$ & 39.708 & 127.370 & .312 & & & & & \\
\hline IRON.SEROM & Time & $\begin{array}{l}\text { Sphericity } \\
\text { Assumed }\end{array}$ & 29250.208 & 2 & 14625.104 & 14.624 & .000 & .230 & 29.249 & .999 \\
\hline IRON.SEROM & $\begin{array}{l}\text { Time* } \\
\text { Group1 }\end{array}$ & $\begin{array}{l}\text { Sphericity } \\
\text { Assumed }\end{array}$ & 1598.228 & 2 & 799.114 & .799 & .453 & .016 & 1.598 & .183 \\
\hline IRON.SEROM & Error(Time) & $\begin{array}{l}\text { Sphericity } \\
\text { Assumed }\end{array}$ & 98004.157 & 98 & 1000.042 & & & & & \\
\hline TIBC & Time & $\begin{array}{l}\text { Greenhouse- } \\
\text { Geisser }\end{array}$ & 65970.480 & 1.648 & 40026.962 & 12.705 & .000 & .213 & 20.939 & .989 \\
\hline TIBC & $\begin{array}{l}\text { Time * } \\
\text { Group1 }\end{array}$ & $\begin{array}{l}\text { Greenhouse- } \\
\text { Geisser }\end{array}$ & 6333.501 & 1.648 & 3842.791 & 1.220 & .295 & .025 & 2.010 & .237 \\
\hline TIBC & Error(Time) & $\begin{array}{l}\text { Greenhouse- } \\
\text { Geisser }\end{array}$ & 244052.483 & 77.463 & 3150.564 & & & & & \\
\hline
\end{tabular}

Tables-8.The descriptive statistics of the time between taking drug and death, Results of ManWhitney test showed that the difference of death time between drug and placebo was not significant.

\begin{tabular}{|llllll|}
\hline & Group & N & Mean & Std. Deviation & Std. Error Mean \\
\hline Time & 4,5 & 2 & 15.0000 & 4.24264 & 3.00000 \\
\cline { 2 - 6 } & 6,7 & 3 & 11.0000 & 5.19615 & 3.00000 \\
\hline
\end{tabular}

\section{Discussion}

The clinical signs of COVID-19 range greatly, from moderate to severe cases of atypical pneumonia, with some developing acute respiratory distress syndrome (ARDS), which frequently necessitates invasive mechanical ventilation and is the major cause of mortality. The severity of the respiratory disease caused by SARS-CoV-2 is thought to be largely owing to an increased immunological response to the virus and CCS[5, 30-33].

Oxidative stress is a feature of COVID-19 disease, which is connected to the CSS seen in the patients with severe COVID-19[34, 35]. Selenium is essential to boost immunity, lower oxidative stress and prevent viral infections, resulting in amelioration of severe diseases[18]. As a result, selenium supplementation can be used as a supportive treatment for COVID-19 infection, and various researches have therefore looked into justification for randomized, controlled trials of selenium supplementation in the disease caused by SARS-CoV-2[18, 36, 37].

On the other hand, iron is a vital trace element both for humans and virus including coronaviruses. Numerous studies have shown that iron is necessary for viral infections and appears to be critical for the replication of SARS-CoV and MERS-CoV as well[38]. In viral infections, changes occur in the body's iron metabolism aiming to seize iron and limit the virus access to this vital metal. However, these events, which are centered on 
proinflammatory cytokines including IL-6, lead to altered iron metabolism and increased oxidative stress via the Fenton reaction, which results in ferroptosis and the continuation of oxidative harm to biomolecules that finally damage the organs in the body $[39,40]$.

In fact, inflammation, oxidative stress and altered iron homeostasis are inextricably connected at a systemic level[41]. This viewpoint emphasizes the possible role of altered iron homeostasis as well as its potential significance in COVID-19 pathogenesis and management strategies[42, 43]. Surprisingly, in the natural immunity of the body, there are iron chelators whose antiviral effects are proved in numerous studies. Lactoferrin (Lf) is a widely distributed glycoprotein generated by a variety of mucosal epithelial cells and is an important component of the natural immunity. This protein has the ability to chelate iron and its antiviral capacity is demonstrated in previous studies[44], and even several researches have discussed its potential for antiviral therapy in COVID-19 patients.

As a result, in view of the vital role of this element for hemoglobin synthesis and other physiological processes, iron chelation therapy can be used as a strategy for managing iron dis-homeostasis with the aim of iron redistribution and sequestration to make iron inaccessible to viruses, while preventing its excretion. It should be noted that the existing iron chelators have many limitations making them incapable of such smart therapeutic behavior. Amongst the existing chelators, deferiprone has shown higher capability to redistribute iron in various experiments [45, 46]. However, although the existing iron chelators have demonstrated promising impacts on viral diseases - mostly in vitro \& rarely clinical studies - they are not yet nominated as serious operational candidates for the treatment of viral diseases due to their side effects \& structural limitations. These limitations are to such an extent - even in their specific field of application (i.e., iron excretion in diseases caused by iron overload) - that there is a serious need for safer \& more efficient chelators[47].

In the previous studies, we reported the successful effects of BCc1 nanochelating-based iron chelator in animal and clinical studies. This nanomedicine increased the survival and quality of life of metastatic and non-metastatic gastric cancer patients without any side effects[21, 48] and showed nephroprotective and antioxidative effects in the animal model of chronic kidney disease[22]

Given the proved impact of iron and selenium on the antiviral performance of the immune system and in light of the results of the previously reported study on BCc1 nanomedicine, the safety and immunomodulatory effect of the combination of BCc1 and selenium-containing Hep-S nanomedicines on hospitalized COVID-19 patients were evaluated in the current study.

The results showed that adding the combination therapy of BCc1 and Hep-S nanomedicines to the standard treatment regimen of hospitalized COVID-19 patients had no negative effect on their hematological characteristics. As explained in the results section, the characteristics linked to the physiological function of iron, such as hemoglobin, red blood cell count and hematocrit, were assessed in this study, and the results showed that despite the iron chelating property of $\mathrm{BCc} 1$, the combination therapy of $\mathrm{BCc} 1$ and Hep-S had no negative impact on the indices. The results of this study were in line with the results of the study on gastric cancer patients conducted by Hafizi et al., demonstrating that the 18-month consumption of BCc1 nanomedicine had no negative effect on hematological indices compared to the placebo group[21] .

Studies have reported increase in the plasma levels of IL-6 and TNF-alpha in hospitalized COVID-19 patients[49]. The higher level of IL-6 concentration is closely related with the requirement for ventilatory assistance and the development of respiratory failure[50]. Suppressing this cytokine therefore results in managing clinical symptoms, shortening hospitalization period and decreasing need for oxygen therapy[51]. According to the CSS pathogenesis in COVID-19, immunomodulatory therapy can be a proper consideration in this disease[52]. Immunomodulatory medications, which operate by modifying or harnessing the immune responses, come with a number of disadvantages and side effects that can negatively impact patients' quality of life. Unwanted side effects, such as severe infections, cytokine release syndrome, anaphylaxis and hypersensitivity as well as immunogenicity, make developing novel and safer immunomodulatory structures difficult[53, 54].

Since IL-6 is a relevant cytokine in acute respiratory distress syndrome, the blockade of its receptor with tocilizumab (TCZ) in COVID-19 patients has been evaluated in numerous studies. Some showed the beneficial effect of this medicine on reducing mortality rate and hospitalization time[55], while several experiments showed its failure[56] and even did not support its use for the management of cytokine storm in COVID-19 patients[57]. Also, several studies reported that the incidence of infectious complications in patients receiving TCZ was higher than in patients receiving standard therapies[55].

In the present study, consuming the combination of BCc1 and Hep-S nanomedicines for 28 days reduced IL- 6 cytokine significantly and could also reduce the numeral value of TNF-a. In addition, the comparison of the treatment and placebo groups showed that these two nanomedicines could decrease IL-6/IFN- $\gamma$ ratio; the higher this ratio is, the more serious the CSS and damage to lungs will be[58]. Moreover, at the end of the treatment period, the percentage of NK cells in the treatment group was numerically lower, and the level of IgM antibody had a decreasing trend compared to the placebo. These results could be therefore attributed to the regulatory effect of the nanomedicines on the immune system to accelerate passing through acute inflammatory phase[59].

There was no significant difference between the treatment and placebo groups in terms of hospitalization period. As this study was conducted at the second peak of COVID-19 disease, the patients were discharged from the hospital as soon as their standard treatment period (remdesivir, etc.) was finished so that new COVID-19 patients could be admitted to the hospital. As a result of this, it was practically impossible to compare the

Page 13/23 
hospitalization period of the patients in both groups. The results also showed that there were two death cases in the treatment group and three in the placebo.

Moreover, none of the observed clinical symptoms deteriorated in the treatment patients, and they also showed less need for oxygen therapy, leading to higher satisfaction in the treatment group compared to the placebo. Therefore, the combination therapy of BCc1 and Hep-S along with the standard protocol showed no adverse effects and yet had immunomodulatory impacts. One reason for the immunomodulatory effect of these two nanomedicines, without causing any side effects - abnormal changes in blood haemato- and biochemical parameters, negative clinical symptoms, etc. - during 28 days of consumption, is their smart impact on the metabolism of two vital elements of iron and selenium by benefiting from their unique high-tech structure.

Studies show that iron chelation exhibits antiviral and immunomodulatory effects in vitro[60] and in vivo, can attenuate ARDS and help control SARS-CoV-2[42]. In addition, there is a risk of selenium insufficiency in immunopathological conditions, and as a result of this, blood selenium levels are more likely to decline. According to studies, serum IL-6 concentrations are inversely linked to serum selenium[61, 62]. Selenium-deficient cells generate more IL-6 in human bronchial epithelial cell lines infected with influenza virus[63]. There is also evidence that selenium supplementation can reduce excessive cytokine production[64]. As selenium status influences SARS-CoV-2 infection-induced immunopathogeneses, maintaining optimal selenium intake seems vital. Furthermore, studies suggest that selenium status is related to mortality and cure rate of COVID-19 patients[65-68]. There has been evidence of rise in cure rate after selenium intake due mainly to the induction of optimal levels of production and activation of selenoprotein with various functions including antioxidative, anti-inflammatory, immunomodulatory and cellular redox homeostasis maintenance, which help combat COVID-19 pathophysiological events[36].

The previous studies on nanochelating-based structures have evaluated and proved the immunomodulatory effects of these structures. In an animal model of multiple sclerosis as an autoimmune disorder, Fakharzadeh et al. showed that MSc1 nanochelating-based iron chelator could prompt therapeutic behavior, improve the disabling features of experimental autoimmune encephalomyelitis and decrease lymphocyte infiltration in central nervous system[23]. In another study, selenium and zinc-containing DIBc metal organic framework demonstrated antidiabetic effects and lowered TNF-a level efficiently[69].

Thus, it seems that the nanochelating technology has presented a new generation of immunomodulators with unique structures that do not suffer from limitations such adverse reactions.

\section{Conclusion}

The present study showed that the combination of BCc1 and Hep-S nanomedicines along with the standard treatments of COVID-19 is a safe treatment which has immunomodulatory effects through reducing IL-6 (as an important mediator of CCS), so they can be studied and evaluated in larger populations for moderate as well as sever COVID-19 patients.

\section{Declarations}

\section{Ethics Approval and Consent to Participate}

This trial is registered with Iranian Registry of Clinical Trials; Reg. No. IRCT20170731035423N2. It has also received the ethic approval of Shahid Beheshti University of Medical Sciences, Tehran, Iran; Reg. No. IR.SBMU.CRC.REC.1399.001.

\section{Consent for publication}

Not applicable

\section{Consent to participate}

Not applicable

\section{Availability of data materials}

The datasets generated during the current study are available from the corresponding author on reasonable request

\section{Funding}

Not applicable

\section{Authors' contributions}


$\mathrm{MH}$ and SF performed most of the experiments and data acquisition and also wrote the manuscript. SK carried out the synthesis of the BCc1 nanomedicine.

AF, SL, SM, MM, JH, MB, HZ, AN,MP and SY collected the data and selected the patients. MHN contributed to the conception and design of the BCc1 nanomedicine. MEA and $\mathrm{HJ}$ designed the study. All authors read and approved the final manuscript.

\section{Conflicts of interest}

The authors state that there are no competing interests.

\section{Acknowledgements}

We do appreciate the support of the Department of Research and Development at Sodour Ahrar Shargh Company, Tehran, Iran and we also thanks the nursing staff of Masih Daneshvari Hospital, including Ms Behrad,Dehghani and Asemabadi.

\section{References}

1. CoV-2, s.a.r.s.

2. Kuba, K., et al., A crucial role of angiotensin converting enzyme 2 (ACE2) in SARS coronavirus-induced lung injury. Nat Med, 2005. 11(8): p. 8759.

3. Raj, V.S., et al., Dipeptidyl peptidase 4 is a functional receptor for the emerging human coronavirus-EMC. Nature, 2013. 495(7440): p. 251-4.

4. Channappanavar, R. and S. Perlman, Pathogenic human coronavirus infections: causes and consequences of cytokine storm and immunopathology. Semin Immunopathol, 2017. 39(5): p. 529-539.

5. Mehta, P., et al., COVID-19: consider cytokine storm syndromes and immunosuppression. Lancet, 2020. 395(10229): p. 1033-1034.

6. Atal, S. and Z. Fatima, IL-6 Inhibitors in the Treatment of Serious COVID-19: A Promising Therapy? Pharmaceut Med, 2020. 34(4): p. 223-231.

7. Becer, H.S.V.a.E., Relationship between IL-6 and COVID-19: to be considered during treatment. 2020.

8. Chung, J.Y., M.N. Thone, and Y.J. Kwon, COVID-19 vaccines: The status and perspectives in delivery points of view. Adv Drug Deliv Rev, 2021. 170: p. 1-25.

9. https://www.who.int/publications/i/item/WHO-2019-nCoV-therapeutics-2021.1.

10. Qiu, R., et al., The therapeutic effect and safety of the drugs for COVID-19: A systematic review and meta-analysis. Medicine (Baltimore), 2021. 100(16): p. e25532.

11. Aygun, I., M. Kaya, and R. Alhajj, Identifying side effects of commonly used drugs in the treatment of Covid 19. Sci Rep, 2020. 10(1): p. 21508.

12. Drakesmith, H. and A. Prentice, Viral infection and iron metabolism. Nat Rev Microbiol, 2008. 6(7): p. 541-52.

13. McDermid, J.M., et al., Mortality in HIV infection is independently predicted by host iron status and SLC11A1 and HP genotypes, with new evidence of a gene-nutrient interaction. Am J Clin Nutr, 2009. 90(1): p. 225-33.

14. Taneri, P.E., et al., Anemia and iron metabolism in COVID-19: a systematic review and meta-analysis. Eur J Epidemiol, 2020. 35(8): p. 763-773.

15. Lv, Y., et al., Association between iron status and the risk of adverse outcomes in COVID-19. Clin Nutr, 2021. 40(5): p. 3462-3469.

16. Avery, J.C. and P.R. Hoffmann, Selenium, Selenoproteins, and Immunity. Nutrients, 2018. 10(9).

17. Hoffmann, P.R. and M.J. Berry, The influence of selenium on immune responses. Mol Nutr Food Res, 2008. 52(11): p. 1273-80.

18. Khatiwada, S. and A. Subedi, A Mechanistic Link Between Selenium and Coronavirus Disease 2019 (COVID-19). Curr Nutr Rep, 2021. 10(2): $\mathrm{p}$. 125-136.

19. Karimi-Sales, R., et al., Neuroprotective Effect of New Nanochelating-Based Nano Complex, ALZc3, Against Abeta (1-42)-Induced Toxicity in Rat: a Comparison with Memantine. Pharm Res, 2020. 37(3): p. 48.

20. Fakharzadeh, S., et al., DIBC nano metal-organic framework improves biochemical and pathological parameters of experimental chronic kidney disease. J Trace Elem Med Biol, 2020. 61: p. 126547.

21. Hafizi, M., et al., A randomized, double-blind, placebo-controlled investigation of BCc1 nanomedicine effect on survival and quality of life in metastatic and non-metastatic gastric cancer patients. J Nanobiotechnology, 2019. 17(1): p. 52.

22. Fakharzadeh, S., et al., BCc1 Nanomedicine Therapeutic Effects in Streptozotocin and High-Fat Diet Induced Diabetic Kidney Disease. Diabetes Metab Syndr Obes, 2020. 13: p. 1179-1188.

23. Fakharzadeh, S., et al., The therapeutic effects of MSc1 nanocomplex, synthesized by nanochelating technology, on experimental autoimmune encephalomyelitic C57/BL6 mice. Int J Nanomedicine, 2014. 9: p. 3841-53.

24. Fakharzadeh, S., et al., The new nano-complex, Hep-c, improves the immunogenicity of the hepatitis B vaccine. Vaccine, 2013. 31(22): p. 25917.

25. MH, N., Chelate compounds. United States patent US 8288587 B2. Oct 16, 2012. 
26. Kalanaky, S., et al., BCc1, the novel antineoplastic nanocomplex, showed potent anticancer effects in vitro and in vivo. Drug Des Devel Ther, 2016. 10: p. 59-70.

27. Chang, Y.C., et al., Pulmonary sequelae in convalescent patients after severe acute respiratory syndrome: evaluation with thin-section CT. Radiology, 2005. 236(3): p. 1067-75.

28. Mortaz, E., et al., The Immune Response and Immunopathology of COVID-19. Front Immunol, 2020. 11: p. 2037.

29. Fiteni, F., et al., Endpoints in cancer clinical trials. J Visc Surg, 2014. 151(1): p. 17-22.

30. Siddiqi, H.K. and M.R. Mehra, COVID-19 illness in native and immunosuppressed states: A clinical-therapeutic staging proposal. J Heart Lung Transplant, 2020. 39(5): p. 405-407.

31. Guaraldi, G., et al., Tocilizumab in patients with severe COVID-19: a retrospective cohort study. Lancet Rheumatol, 2020. 2(8): p. e474-e484.

32. Xu, X., et al., Effective treatment of severe COVID-19 patients with tocilizumab. Proc Natl Acad Sci U S A, 2020. 117(20): p. 10970-10975.

33. Sciascia, S., et al., Pilot prospective open, single-arm multicentre study on off-label use of tocilizumab in patients with severe COVID-19. Clin Exp Rheumatol, 2020. 38(3): p. 529-532.

34. Wang, H., et al., Possible immunity, inflammation, and oxidative stress mechanisms of Alzheimer's disease in COVID-19 patients. Clin Neurol Neurosurg, 2021. 201: p. 106414.

35. Cecchini, R. and A.L. Cecchini, SARS-CoV-2 infection pathogenesis is related to oxidative stress as a response to aggression. Med Hypotheses, 2020. 143: p. 110102.

36. Zhang, J., et al., Selenium and selenoproteins in viral infection with potential relevance to COVID-19. Redox Biol, 2020. 37: p. 101715.

37. Liu, Q., et al., Selenium (Se) plays a key role in the biological effects of some viruses: Implications for COVID-19. Environ Res, 2021. 196: p. 110984.

38. Liu, W., et al., Depriving Iron Supply to the Virus Represents a Promising Adjuvant Therapeutic Against Viral Survival. Curr Clin Microbiol Rep, 2020: p. 1-7.

39. Kell, D.B. and E. Pretorius, Serum ferritin is an important inflammatory disease marker, as it is mainly a leakage product from damaged cells. Metallomics, 2014. 6(4): p. 748-73.

40. Edeas, M., J. Saleh, and C. Peyssonnaux, Iron: Innocent bystander or vicious culprit in COVID-19 pathogenesis? Int J Infect Dis, 2020. 97: p. 303-305.

41. Kernan, K.F. and J.A. Carcillo, Hyperferritinemia and inflammation. Int Immunol, 2017. 29(9): p. 401-409.

42. Dalamaga, M., I. Karampela, and C.S. Mantzoros, Commentary: Could iron chelators prove to be useful as an adjunct to COVID-19 Treatment Regimens? Metabolism, 2020. 108: p. 154260.

43. Birlutiu, V., R.M. Birlutiu, and L. Chicea, Off-label tocilizumab and adjuvant iron chelator effectiveness in a group of severe COVID-19 pneumonia patients: A single center experience. Medicine (Baltimore), 2021. 100(18): p. e25832.

44. Berlutti, F., et al., Antiviral properties of lactoferrin-a natural immunity molecule. Molecules, 2011. 16(8): p. 6992-7018.

45. Saxena, D., et al., Drug-Based Lead Discovery: The Novel Ablative Antiretroviral Profile of Deferiprone in HIV-1-Infected Cells and in HIV-Infected Treatment-Naive Subjects of a Double-Blind, Placebo-Controlled, Randomized Exploratory Trial. PLoS One, 2016. 11(5): p. e0154842.

46. Kontoghiorghe, C.N. and G.J. Kontoghiorghes, New developments and controversies in iron metabolism and iron chelation therapy. World J Methodol, 2016. 6(1): p. 1-19.

47. Abbina, S., et al., Design of Safe Nanotherapeutics for the Excretion of Excess Systemic Toxic Iron. ACS Cent Sci, 2019.5 (5): p. 917-926.

48. Maryam Hafizi , S.K., Hassan Moaiery , Maryam Khayamzadeh, Sajad Noorian, An Investigation on the Effect of BCc1 Nanomedicine on Gastric Cancer Patients Using EORTC QLQ-STO30 Questionnaire.

49. Del Valle, D.M., et al., An inflammatory cytokine signature predicts COVID-19 severity and survival. Nat Med, 2020. 26(10): p. 1636-1643.

50. Nasonov, E. and M. Samsonov, The role of Interleukin 6 inhibitors in therapy of severe COVID-19. Biomed Pharmacother, 2020. 131: p. 110698.

51. Liu, D., et al., Tocilizumab: The Key to Stop Coronavirus Disease 2019 (COVID-19)-Induced Cytokine Release Syndrome (CRS)? Front Med (Lausanne), 2020. 7: p. 571597.

52. Zhao, M., Cytokine storm and immunomodulatory therapy in COVID-19: Role of chloroquine and anti-IL-6 monoclonal antibodies. Int J Antimicrob Agents, 2020. 55(6): p. 105982.

53. Bascones-Martinez, A., et al., Immunomodulatory drugs: oral and systemic adverse effects. Med Oral Patol Oral Cir Bucal, 2014. 19(1): p. e2431.

54. Sathish, J.G., et al., Challenges and approaches for the development of safer immunomodulatory biologics. Nat Rev Drug Discov, 2013. 12(4): p. 306-24.

55. Strohbehn, G.W., et al., COVIDOSE: Low-dose tocilizumab in the treatment of Covid-19. medRxiv, 2020.

56. Roche provides an update on the phase III COVACTA trial of Actemra/RoActemra in hospitalised patients with severe COVID-19 associated pneumonia.

Page 16/23 
57. Tsai, A., et al., Impact of tocilizumab administration on mortality in severe COVID-19. Sci Rep, 2020. 10(1): p. 19131.

58. Lagunas-Rangel, F.A. and V. Chavez-Valencia, High IL-6/IFN-gamma ratio could be associated with severe disease in COVID-19 patients. J Med Virol, 2020. 92(10): p. 1789-1790.

59. Alrubayyi, A., NK cells in COVID-19: protectors or opponents? Nat Rev Immunol, 2020. 20(9): p. 520.

60. Williams, A. and D. Meyer, Desferrioxamine as immunomodulatory agent during microorganism infection. Curr Pharm Des, 2009. 15(11): p. 1261-8.

61. Mahmoodpoor, A., et al., The Effect of Intravenous Selenium on Oxidative Stress in Critically III Patients with Acute Respiratory Distress Syndrome. Immunol Invest, 2019. 48(2): p. 147-159.

62. Tseng, C.K., et al., Selenium is inversely associated with interleukin-6 in the elderly. J Nutr Health Aging, 2013. 17(3): p. 280-4.

63. Jaspers, I., et al., Selenium deficiency alters epithelial cell morphology and responses to influenza. Free Radic Biol Med, 2007. 42(12): p. 182637.

64. Manzanares, W., et al., High-dose selenium reduces ventilator-associated pneumonia and illness severity in critically ill patients with systemic inflammation. Intensive Care Med, 2011. 37(7): p. 1120-7.

65. Im, J.H., et al., Nutritional status of patients with COVID-19. Int J Infect Dis, 2020. 100: p. 390-393.

66. Zhang, J., et al., Association between regional selenium status and reported outcome of COVID-19 cases in China. Am J Clin Nutr, 2020. 111(6): p. 1297-1299.

67. This study in China reports an asociation between selenium status in cities and cure rates from COVID-19 disease.

68. This study found an association between COVID-19 mortality risk and selenium status.

69. Fakharzadeh, S., et al., DIBc, a nanochelating-based nano metal-organic framework, shows anti-diabetic effects in high-fat diet and streptozotocin-induced diabetic rats. Int J Nanomedicine, 2019. 14: p. 2145-2156.

\section{Tables}

Table 6 is not available with this version.

\section{Figures}


Figure 1

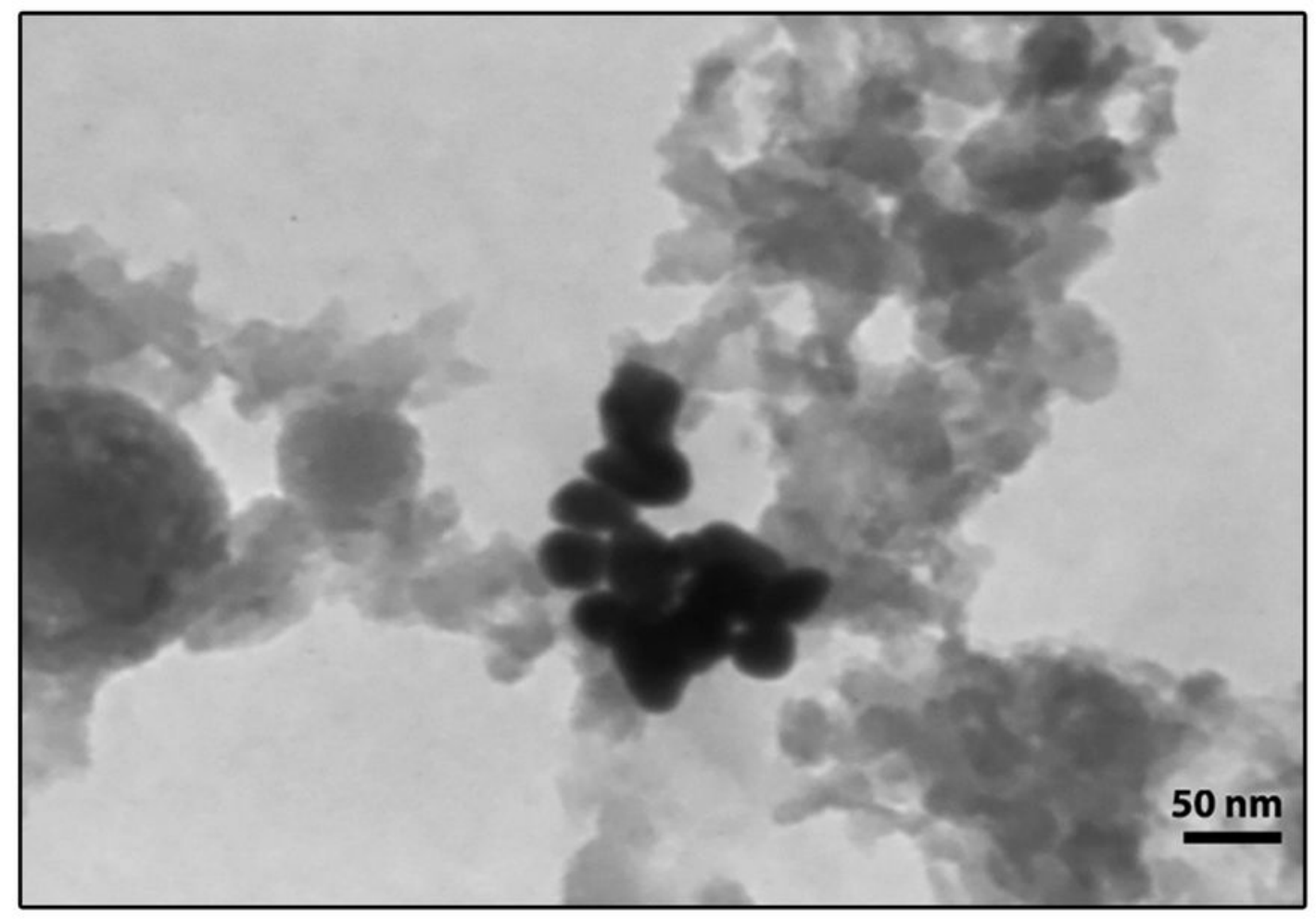

Figure 1

TEM image of Hep-s 
Figure 2

Group

官 Drug

官 Placebo
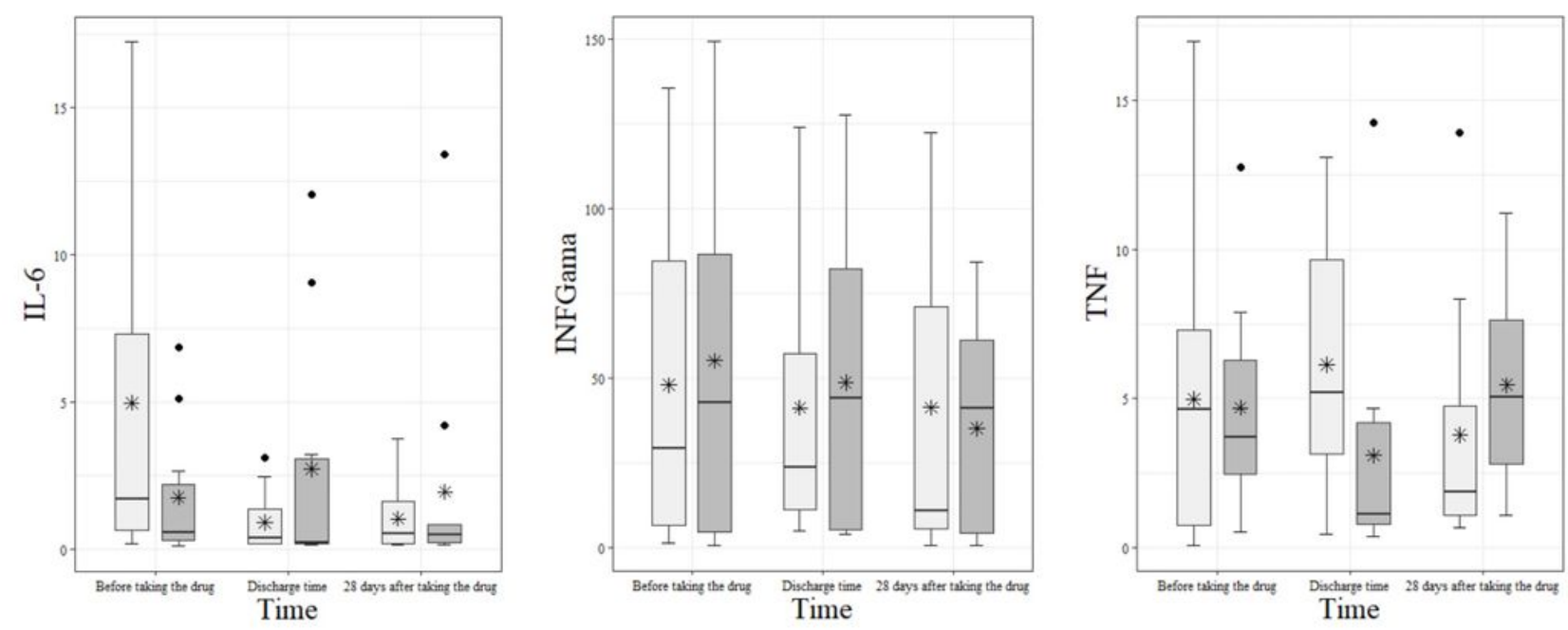

Figure 2

Comparison of dot plot diagram of three cytokines (IL6, TNFa and TNFY) of patients in the Combination of BCc1 and Hep-S group with patients in the placebo group before medicine consumption, at discharge of hospital and 28 days after consumption. 
Figure 3
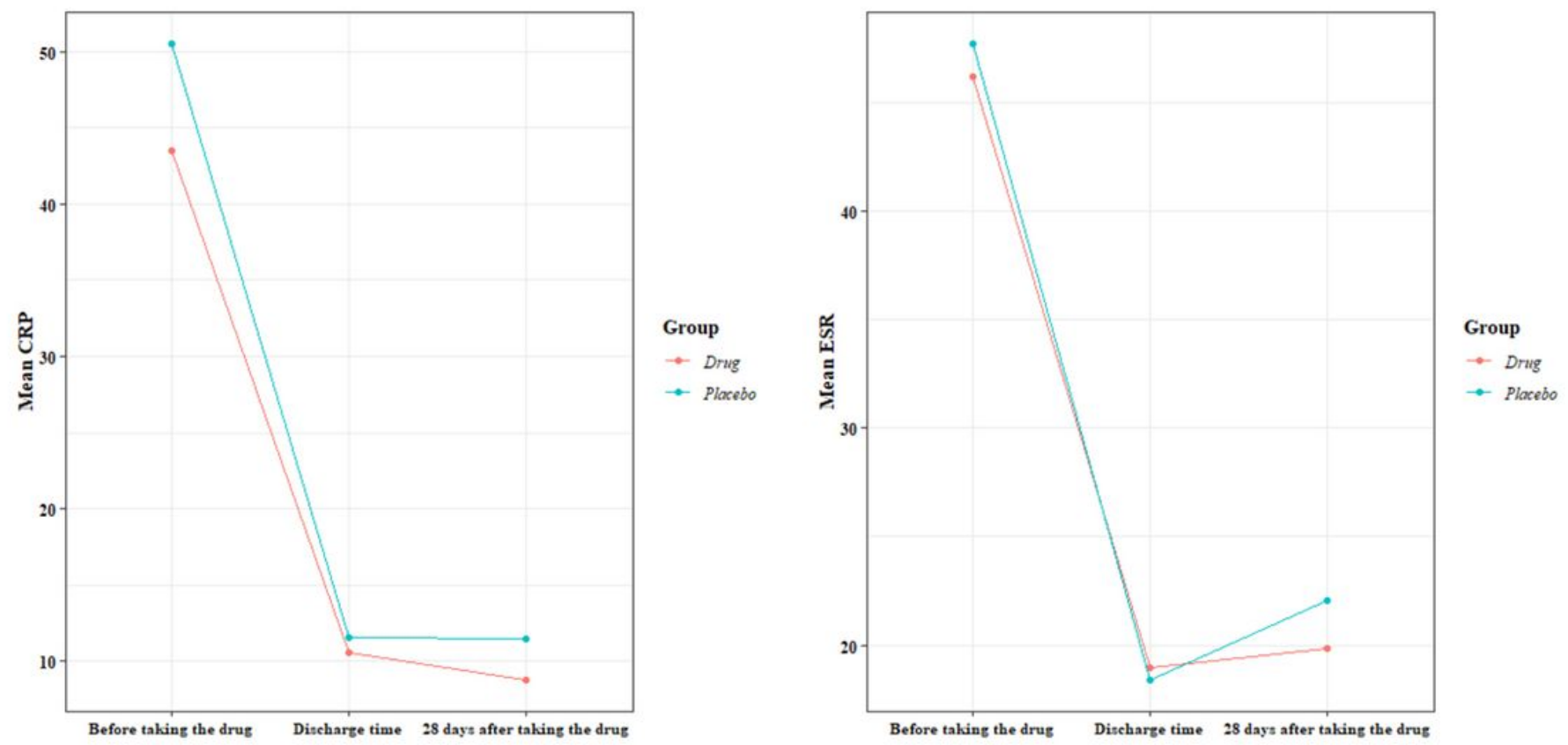

Figure 3

Comparison diagram of CRP and ESR of patients in the Combination of BCc1 and Hep-S group with patients in the placebo group before medicine consumption, at discharge of hospital and 28 days after consumption. 
Figure 4
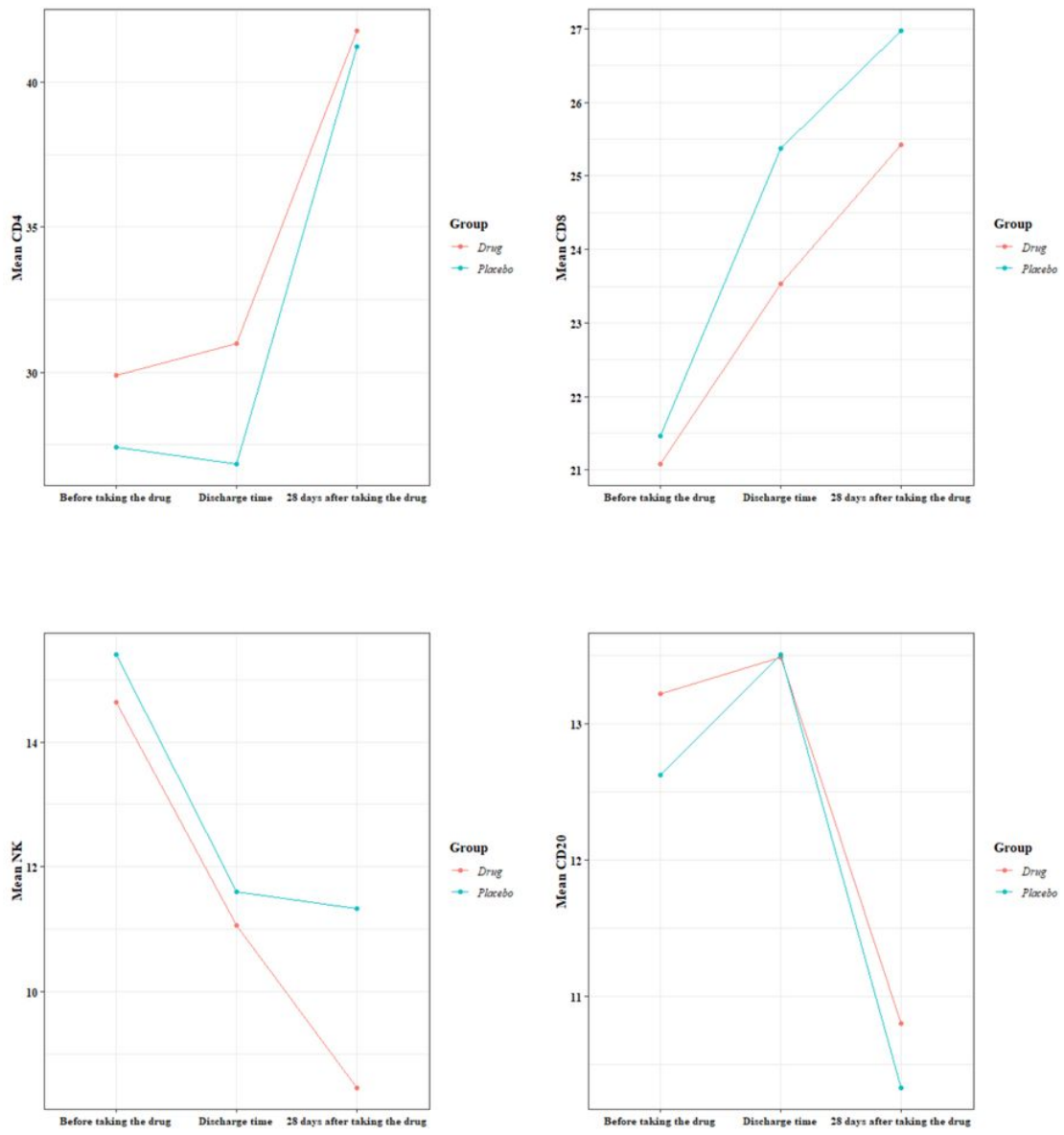

\section{Figure 4}

Comparison diagram of four Expression of CD markers (CD4, CD8, CD20-NK Cells) of patients in the Combination of BCc1 and Hep-S group with patients in the placebo group before medicine consumption, at discharge of hospital and 28 days after consumption. 


\section{Figure 5}
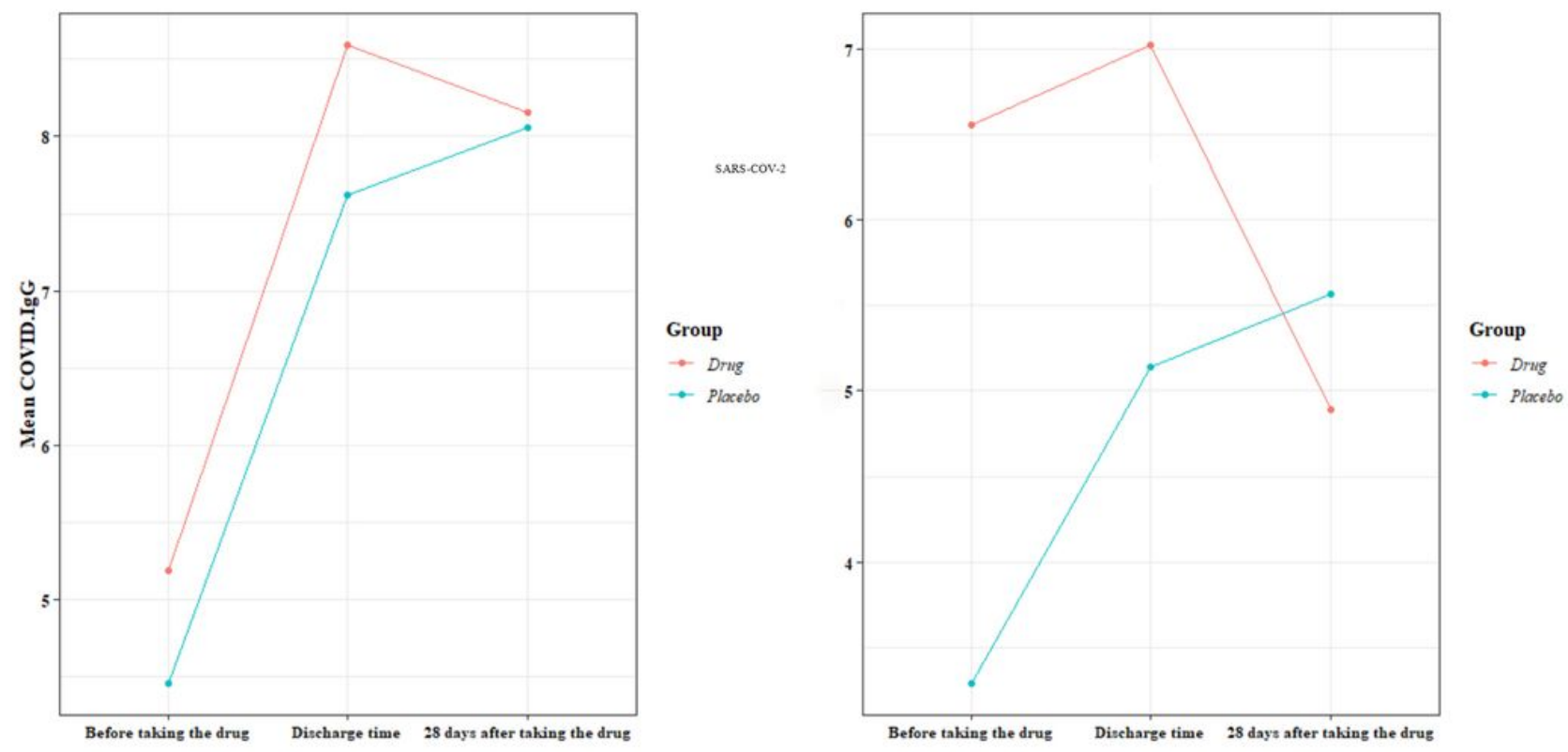

Figure 5

Comparison diagram of COVID-19 antibodies (IgM and $\lg$ ) of patients in the Combination of BCc1 and Hep-S group with patients in the placebo group before medicine consumption, at discharge of hospital and 28 days after consumption.

\section{Image not available with this version}

\section{Figure 6}

Comparison diagram of Clinical parameters of patients in the Combination of BCc1 and Hep-S group with patients in the placebo group before the start of the treatment and on days $3,6,10,15,20$ and 27. 
Figure 7
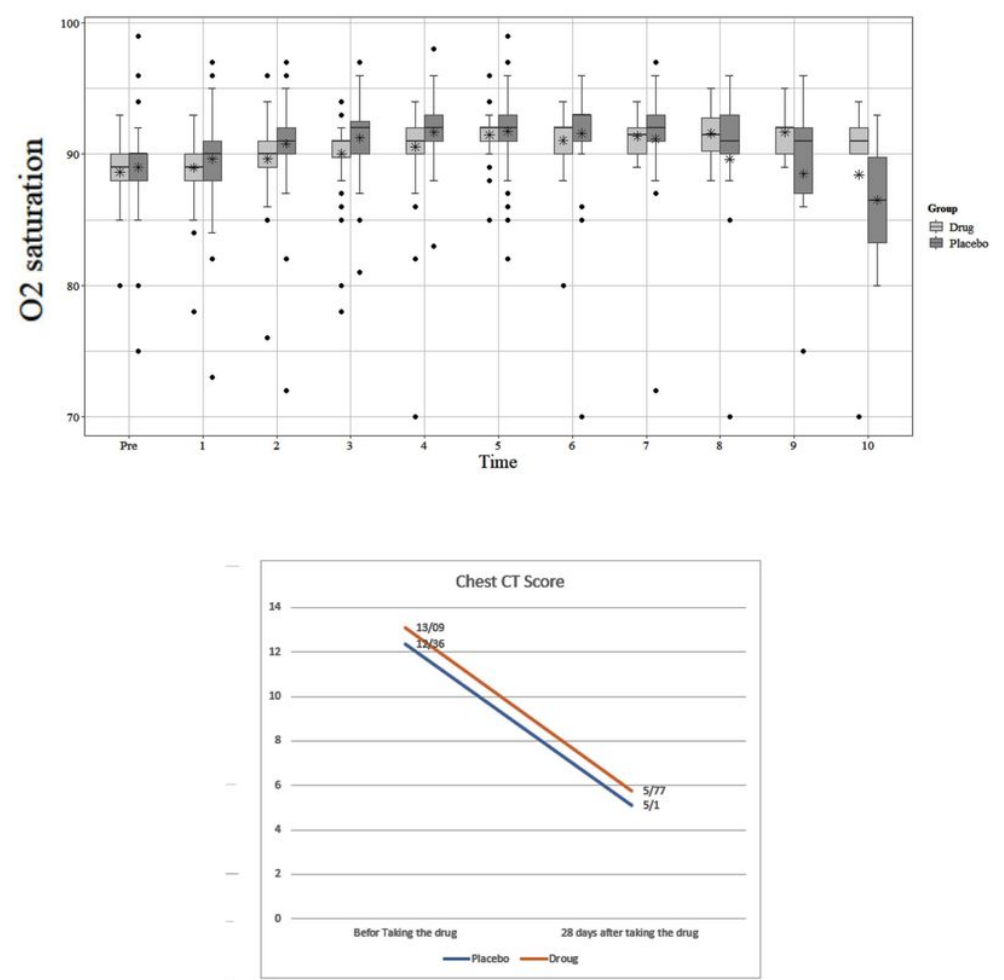

Figure 7

Comparison diagram of CT scanning, oxygen saturation of patients in the Combination of BCc1 and Hep-S group with patients in the placebo group. 